\title{
BMJ Open Comparative cervical profiles of adult and under-18 front-row rugby players: implications for playing policy
}

\author{
D F Hamilton, ${ }^{1}$ D Gatherer, ${ }^{2}$ J Robson, ${ }^{3}$ N Graham, ${ }^{3}$ N Rennie, ${ }^{3}$ J G B MacLean, ${ }^{4}$ \\ A H R W Simpson ${ }^{1}$
}

To cite: Hamilton DF, Gatherer D, Robson J, et al. Comparative cervical profiles of adult and under-18 frontrow rugby players: implications for playing policy. BMJ Open 2014;4: e004975. doi:10.1136/ bmjopen-2014-004975

- Prepublication history for this paper is available online. To view these files please visit the journal online (http://dx.doi.org/10.1136/ bmjopen-2014-004975).

Received 31 January 2014 Revised 9 April 2014 Accepted 11 April 2014
CrossMark

For numbered affiliations see end of article.

Correspondence to Dr David Hamilton; d.f.hamilton@ed.ac.uk

\section{ABSTRACT}

Objective: To compare the cervical isometric strength, fatigue endurance and range of motion of adult and under-18 age-grade front-row rugby players to inform the development of a safe age group policy with particular reference to scrummaging.

Design: Cross-sectional cohort study.

Setting: 'Field testing' at Murrayfield stadium. Participants: 30 high-performance under-18 players and 22 adult front-row rugby players.

Outcome measures: Isometric neck strength, height, weight and grip strength.

Results: Youth players demonstrated the same height and grip strength as the adult players; however, the adults were significantly heavier and demonstrated substantially greater isometric strength $(\mathrm{p}<0.001)$. Only two of the 'elite' younger players could match the adult mean cervical isometric strength value. In contrast to school age players in general, grip strength was poorly associated with neck strength $(r=0.2)$ in front-row players; instead, player weight $(r=0.4)$ and the number of years' experience of playing in the front row $(r=0.5)$ were the only relevant factors in multivariate modelling of cervical strength $\left(R^{2}=0.3\right)$.

Conclusions: Extreme forces are generated between opposing front rows in the scrum and avoidance of mismatch is important if the risk of injury is to be minimised. Although elite youth front-row rugby players demonstrate the same peripheral strength as their adult counterparts on grip testing, the adults demonstrate significantly greater cervical strength. If older youths and adults are to play together, such findings have to be noted in the development of age group policies with particular reference to the scrum.

\section{INTRODUCTION}

Rugby Union (henceforth Rugby) is the world's most popular contact, or more appropriately collision sport, and carries an injury risk four times greater than semicontact sports such as football/soccer. ${ }^{1}$ The scrum is an iconic and fundamental part of the game, where two 'forward packs' compete for the ball to restart the game following a minor infringement. It is a test of strength and technique where the cervical spine of the

\section{Strengths and limitations of this study}

- A particular strength of this study is the direct physical testing of representative player cohorts and the novel data presented.

- A limitation is the assumed but unsubstantiated link between cervical strength and injury.

- This limitation is mitigated through the relationship between scrum collapse and injury.

opposing front rows are subjected to huge compressive and shear forces of a sufficient magnitude to result in tissue injury and structural failure. $^{2}$

Around $8 \%$ of all injuries in professional rugby are thought to result from the scrum. ${ }^{34}$ Injury events in amateur and youth rugby are thought to be similarly proportioned. ${ }^{5}$ Although 8\% represents a comparatively small proportion of the injury burden, these injuries are likely to be of greater severity and involve the spine. ${ }^{6}$ Despite a typical match consisting of comparatively few scrums (compared to other contact events, such as tackles), around $40 \%$ of all rugby derived acute spinal cord injuries occur in the scrum. ${ }^{7} 8$ Scrum engagement occurs as the head and shoulders of the competing front rows make forceful contact. The force generated in the scrum engagement is thought to be a particular risk factor for injury, through high compressive and shear loads or hyperflexion of the cervical spine. ${ }^{7-9}$ This risk has been somewhat mitigated in recent years by the introduction of 'controlled scrum engagement' where the distance between opposing front rows has been standardised in an attempt to reduce acceleration and thus collision forces. ${ }^{10}{ }^{11}$ Scrum collapse has also been identified as a leading cause of scrum-related injury. ${ }^{7}{ }^{12}$ Premature micro trauma-induced degeneration of the cervical spine in front-row players $^{13}$ and mismatches in size between front-row players ${ }^{7}{ }^{14}$ have been suggested as potential factors for the over-representation of scrum-related injuries, though Brown et al note 
that coaching and technical factors have not been well explored in these analyses.

Body size and physical mismatch are considered (at least in part) to be associated with injury risk in schoolboy rugby. ${ }^{15}$ Some national governing bodies have introduced a weight category banding for youth rugby to address this concern in children who mature skeletally at differing rates. However, once players reach the age of 18 , all participants are considered as adults and no such segregation takes place, and the banding rule no longer applies. Indeed, rugby is a sport that relies on differing physical attributes for the various playing positions. There are circumstances, though, where those yet to reach their 18th birthday may wish to play adult rugby, either through selection processes in the case of particularly gifted players, or through leaving school and joining a club playing in the adult leagues. The policy within Scottish Rugby (prior to the start of the 2013-2014 season) had been that only 'exceptional' 17 -year-old players were eligible to play in the adult leagues; however, there was concern as to the suitability of this policy regarding the front row.

Although adequate cervical strength is relevant to all rugby players, the scrum exposes players' cervical spines to potentially injurious forces that must be attenuated by controlled spinal motion through the cervical musculature, ligaments and intervertebral discs. ${ }^{16}$ Appropriate strength of the cervical musculature is thus particularly important for front-row players. The risk of scrum collapse (and, by extension, associated injuries) is increased if any of the six front-row players cannot maintain the muscular force required to complete the scrum. The overall compressive and shear forces generated in the scrum are only now being defined. These have been demonstrated to vary by playing level, with youth teams generating significantly lower forces than adult sides. ${ }^{2}$ However, the relationship between these overall scrum forces and the mechanisms by which the individual front-row players modulate them has not been explored. We have previously demonstrated large variation in the neck strength of school-aged rugby players; ${ }^{17}$ however, we are not aware of any report of data on maximal strength or fatigue endurance specific to the front-row forwards (either youth or adult). Characterisation of the strength profiles of the cervical spine of this specific group is thus warranted.

The aim of this study was to assess the cervical isometric strength and fatigue endurance of adult and senior school-aged rugby players to assess the ability of under-18 players to compete with adults in the front row of the scrum. A secondary objective was to assess the relationship between isometric strength and various physical parameters (such as age, weight and grip strength) previously shown to predict this.

\section{METHODS}

\section{Study design and sample}

A cross-sectional cohort study was undertaken to investigate the isometric neck strength and fatigue endurance of front-row rugby players. Thirty senior school-aged players (under-18 age-grade) were assessed at Murrayfield stadium in tandem with a Scottish Rugby Union (SRU) arranged front-row coaching session, and 22 adult players in a separate assessment, again at Murrayfield stadium, organised in conjunction with the SRU.

The youth players were drawn from 21 different clubs/schools from across Scotland and represented the 'elite' end of the senior school-aged front-row players in Scotland. The adults were a representative sample of amateur players, drawn from six clubs reflecting the top five playing levels in Scottish club rugby (as defined by the position of their first XV in the Scottish national leagues). This range was decided on to reflect the spectrum of levels that the under-18 group may play. Players were assessed from Dunfermline, Heriots, Murrayfield Wanderers, Musselburgh, Royal High Corstorphine and Watsonian rugby clubs, comprising players from the first, second and third teams. Adult and school-age testing sessions took place at the same facility in the same environment using the same equipment and operators. Participation was voluntary and signed consent was obtained from all participants.

\section{Cervical strength and endurance assessment}

Isometric cervical muscle testing is well validated. ${ }^{18-20}$ We assessed maximal voluntary isometric cervical muscle strength with the GS Gatherer and GS Analysis Suite (Gatherer Systems Ltd, Aylesbury), a custom-built device based on a $300 \mathrm{~kg}$ load cell and bespoke software system.

The test was performed employing a previously reported protocol ${ }^{1721}$ where the head was placed in the neutral anatomic position and subjected to manual controlled incremental loading to positional failure (the point of head movement). Subject report of pain or neurological symptoms also stopped the test. Loading was applied and data were recorded at $20 \mathrm{~Hz}$. Peak isometric force generated by the musculature was defined as the maximal load recorded during the test procedure. An average of three tests is reported, with a $60 \mathrm{~s}$ rest period enforced between assessments.

An assessment of cervical musculature fatigue endurance was made using the same test equipment. The player was required to exert an isometric extension load at $50 \%$ of their recorded mean peak extension force for as long as possible. The player sat in a neutral position with their arms by their side and head connected to the load cell. Players received a visual graphical feedback as to the target load applied via a computer monitor. This allowed for maintenance of a consistent load until failure. A single assessment was made of fatigue.

\section{Anthropometric parameters}

Additional measures were made of: height (Leicester Height Measure; SECA, UK), weight (medical grade mechanical flat scales; SECA, UK), grip strength (JAMAR hydraulic hand dynamometer; Sammoms Preston, Illinois, USA) and cervical range of motion 
(Cervical Range of Motion Instrument, Performance Attainment Associates, Minnesota, USA). Three readings were obtained for each parameter and their average was derived and reported. Prior to the physical assessment, the player's rugby playing history and detail of neckspecific training and injuries were determined using a self-reported questionnaire.

\section{Data analysis}

Data were analysed using Minitab (V.16). Data were checked for normality and are reported as means with SD or $95 \%$ CIs of the mean as a measure of dispersion. Independent sample $t$ tests were used to assess differences in continuous variables between groups unless otherwise stated. Significance was accepted as $\mathrm{p}<0.05$, incorporating the Benjami-Hochberg correction for the testing of multiple hypotheses, to reduce the possibility of making a type $I$ error in the interpretation of results. ${ }^{22} 23$

To assess the secondary research question as to predictive modelling of front-row player neck strength, all data were considered as a single cohort. Pearson correlation coefficients are reported for bivariate correlations. Stepwise regression modelling was performed to achieve the most predictive model for global neck strength (for which we use isometric extension) utilising the fewest variables. Predictive variables were selected if their bivariate significance was $\mathrm{p}<0.1$ to accommodate the possibility of variables achieving statistical significance once the confounding influence of additional variables was controlled. A potential limitation of this approach is that the homogenised under-18 group may cause a clustering effect in the data. Separate analysis of the adult data demonstrates the same relationships as reported for the entire cohort lending credibility to the results presented. Further, all players assessed are eligible to play in the adult leagues and can thus be considered representative of a single cohort in the context of our secondary research question, to assess the influence of various physical variables (previously suggested to reflect the variation in cervical strength in a school-aged population) in the specific situation of the front-row player.

\section{RESULTS}

Large differences were observed between groups in terms of age and experience (years) playing as a front-row forward. There was no difference in height or grip strength between the groups, although the adults were significantly heavier. Cervical range of motion was similar in measures of extension and rotation, although the elite under-18 group had a greater range of cervical flexion and side flexion (table 1 ).

Differences were observed in isometric strength between groups in extension (figure 1 and table 2) and side flexion (table 2); the under-18 group was approximately $20 \%$ weaker than the adult group. A larger variation was seen in all parameters of adult neck strength data compared to the under-18 group. This may be due to the selection bias of elite players in the younger age group, which may have somewhat homogenised these data. Despite this potential positive skew in the under-18 data, only 2 of the 30 elite under- 18 front-row players achieved the adult mean strength value (figure 1).

Only three of the under-18s achieved the adult mean isometric extension fatigue endurance (impulse, table $2)$; this difference between groups was significant at $\mathrm{p}<0.1$, possibly reflecting the large variation in adult scores. The adults performed better in the fatigue assessment, holding significantly higher average loads for the same length of time as the younger players (table 2). Surprisingly, only a quarter of all players reported performing routine neck exercises, split evenly between groups (table 1).

\section{Predictive modelling}

Isometric neck strength was most associated with the experience of playing in the front row $(\mathrm{r}=0.5, \mathrm{p}<0.001$; figure 2), followed by weight $(\mathrm{r}=0.4, \mathrm{p}=0.004)$ and player age $(\mathrm{r}=0.4, \mathrm{p}=0.005)$. In contrast, grip strength correlated relatively poorly $(\mathrm{r}=0.2, \mathrm{p}=0.09$; figure 3$)$. Cervical fatigue endurance was associated with peak isometric extension strength but correlated poorly $(\mathrm{r}=0.30$, $\mathrm{p}=0.08)$. Player weight $(\mathrm{r}=0.6, \mathrm{p}=0.007)$ was the factor most associated with fatigue; again, grip strength correlated poorly $(\mathrm{r}=0.1, \mathrm{p}=0.6)$.

Stepwise regression determined the best predictive model for isometric strength to include the number of years' experience playing in the front row and the players' weight (table 3). The greatest single contributing variable was the experience of playing in the front row, which explained around $22 \%$ of the variation in isometric extension. The same variables also created the best predictive model of fatigue endurance, again explaining around a third of the variation in neck strength $\left(\mathrm{R}^{2}=0.4\right)$.

\section{DISCUSSION}

This study demonstrates that even elite under-18 front-row rugby players, who have participated in a conditioning and strengthening programme, are able to generate significantly less cervical muscle force than adult players. This is relevant when determining the suitability of junior players to compete in the adult game, where significant forces are exerted through the cervical spine of the front-row forwards during the scrum. These forces must be modulated by the cervical musculature, and the reduced isometric strength and fatigue endurance ratings found in the under-18 players puts them at a significant disadvantage, with potentially injurious consequences. The under-18 players in this study were the top front-row players in Scotland, and this sample of players is most likely to be considered appropriate to play in the adult leagues as they may seem physically stronger and bigger. Based on this, it may then be 
Table 1 Anthropometric data by group

\begin{tabular}{llll} 
& & Adult & Significance \\
\hline Age (years) & $16.7(16-17)$ & $27.2(19-50)$ & $<0.001^{*}$ \\
Experience of the front row (years) & $5.0(1-12)$ & $14.3(2-26)$ & $<.001^{*}$ \\
Regular neck strengthening (yes/no) & $7 / 23$ & $5 / 21$ & $0.959 \dagger$ \\
Height (cm) & $178.7(5.54)$ & $178.7(5.91)$ & 0.960 \\
Weight (kg) & $96.0(13.69)$ & $107.8(13.67)$ & $0.004^{*}$ \\
Grip strength (kg) & $47.8(5.31)$ & $49.56(7.56)$ & 0.360 \\
Cervical range of motion (degrees) & & \\
$\quad$ Extension & $65.33(8.70)$ & $65.62(6.62)$ & 0.895 \\
Flexion & $58.50(8.32)$ & $44.10(8.93)$ & $<0001^{*}$ \\
Side flexion (left) & $49.17(5.88)$ & $44.33(6.51)$ & $0.010^{*}$ \\
Side flexion (right) & $45.60(8.93)$ & $41.33(6.18)$ & 0.049 \\
Rotation (left) & $66.50(7.67)$ & $65.90(6.80)$ & 0.772 \\
Rotation (right) & $67.83(8.06)$ & $64.76(6.83)$ & 0.149 \\
\hline Age and experience reported as mean (range), all other variables as mean (SD). & \\
${ }^{*}$ Remains significant at the 0.05 level correcting for multiple testing. & \\
$\dagger \chi^{2}$ test. & &
\end{tabular}

speculated that the difference in neck strength between the general under-18 playing population and adults may be even greater.

Little information is available as to the 'neck strength' of rugby players, either adult or school aged. We previously assessed the cervical isometric strength of Scottish schoolchildren between the ages of 13 and 18 and found a huge variation both within and between year groups. ${ }^{17}$ We are not aware of any other comparable data for adult players or of any study specifically investigating the cervical isometric strength of the front-row forwards. Using multivariate techniques, we previously reported that player age, weight and grip strength (as an objective measure of overall strength) was strongly predictive of isometric neck extension strength in the general school-aged rugby playing population; explaining around two- thirds of the variance in cervical strength. Interestingly, in this analysis, the measure of grip strength was not a strong predictor of cervical strength in this specific group of front-row players, where player weight and number of years of experience

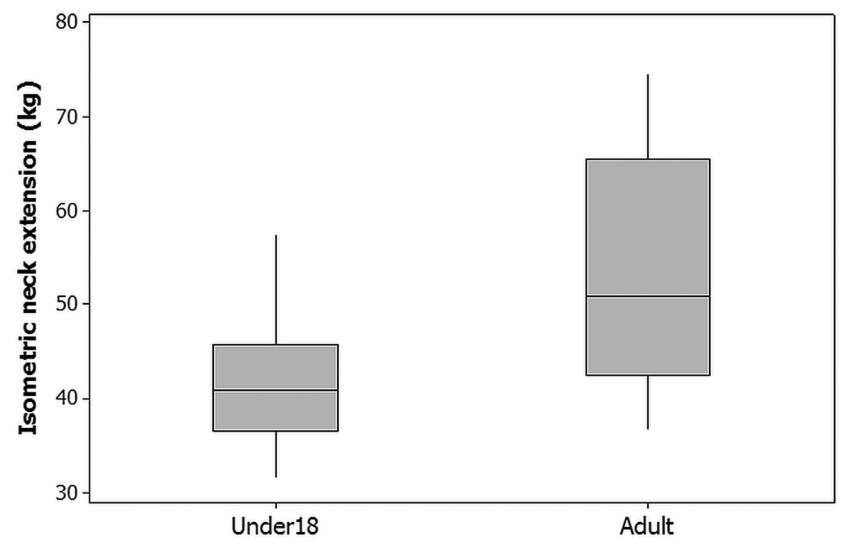

Figure 1 Differences in cervical strength by group. of playing in the front row were the most important factors. This finding may be a reflection of the general lack of neck-specific training performed among rugby players. Only 12 of the 52 players reported having performed any neck-specific exercises. This may suggest that the cervical strength of the players in this study was developed from either generic strength training or from specific scrum training. We propose that the elite under-18 players had reached the same global strength as their adult counterparts through peripheral strength training; however, in the absence of specific structured conditioning, they could not match the cervical strength that the adults had gained as a result of years of competitive scrummaging.

To the best of our knowledge, this is the first report of a cervical musculature fatigue endurance assessment in front-row rugby players of any age. In the absence of previous data, it was necessary to set a safe threshold at which to perform the test; thus, the $50 \%$ submaximal value was selected to determine reference values for adult and under-18 front-row players. While large differences were observed in fatigue endurance values achieved between adult and under-18 players, the large spread of the data in the adult cohort diluted the significance of this finding. Although all players achieved a similar time on fatigue assessment, the $50 \%$ submaximal load held by the under- 18 group (20 kg equivalent) was significantly less than the adult $50 \%$ load ( $25 \mathrm{~kg}$ equivalent), as a result of their lower peak forces on the maximal isometric testing. Now that these benchmark data are available, we recommend that future fatigue endurance assessment of under-18 players should be performed using the mean adult $50 \%$ submaximal value (25 kg equivalent), which would represent around $60 \%$ of the average under-18 maximal isometric value found in this study. It is most likely that greater differences would be apparent between adults and under-18 groups had we been able to employ this testing design and 
Table 2 Cervical strength assessment by group

\begin{tabular}{|c|c|c|c|}
\hline & Under-18 & Adult & Significance \\
\hline \multicolumn{4}{|l|}{ Isometric strength (kg) } \\
\hline Extension & 41.70 (39.36 to 44.18$)$ & 53.70 (48.42 to 58.99$)$ & $<0.001^{\star}$ \\
\hline Flexion & 22.59 (20.45 to 24.72$)$ & 25.40 (22.94 to 27.86$)$ & 0.098 \\
\hline Side flexion (left) & 32.24 (30.04 to 34.45$)$ & 40.53 (36.36 to 44.71$)$ & $0.002^{*}$ \\
\hline Side flexion (right) & 31.83 (29.66 to 24.01$)$ & 42.48 (39.24 to 45.73$)$ & $<0.001^{*}$ \\
\hline \multicolumn{4}{|l|}{ Fatigue } \\
\hline Total (kg s) & 1305 (1181 to 1429$)$ & 1551 (1332 to 1770$)$ & 0.058 \\
\hline Time achieved (s) & $67.10(60.44$ to 83.17$)$ & 71.81 (62.96 to 71.28$)$ & 0.390 \\
\hline Average load (kg) & 18.25 (16.77 to 19.73$)$ & 23.54 (21.35 to 25.73$)$ & $<0.001^{*}$ \\
\hline
\end{tabular}

further help discern those able to compete in the adult front row. Future work should also look at assessing 'scrum-specific' fatigue endurance, looking perhaps at repeated bouts of $80 \%$ submaximal testing over 10-15 s, which could be argued to better reflect the demands of this activity. We suggest this as an area for future research.

Preatoni et $a l^{2}$ assessed the forces generated in the scrum by 34 forward packs at six different playing grades (from senior school to international level) and found notable differences in the forces generated between schools and senior sides. Worryingly, these authors further reported that the combined compression and shear forces they recorded in the scrums were of a sufficient magnitude to induce chronic spine injury. Although further information is needed to understand the link between mechanical forces in the scrum and injury, the shear forces recorded are of particular concern as a risk factor for chronic degeneration of the spine through undesirable rotation and bending motions. The differences in strength characteristics between the adult and under-18 players we describe here suggest that appropriate and specific training

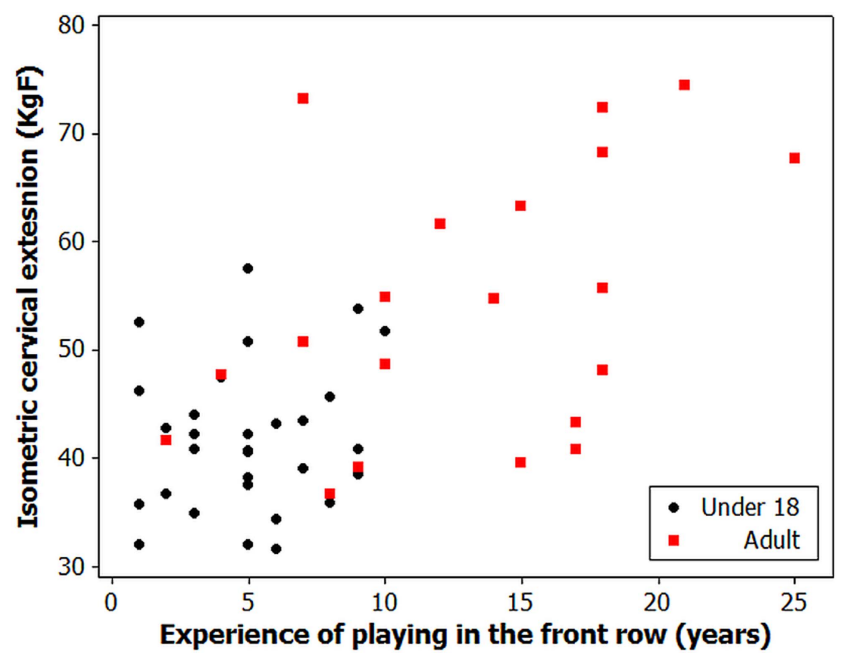

Figure 2 Strong relationship between cervical strength and playing experience. interventions (perhaps through scrum training) are critical in developing the ability to modulate these forces at an individual level.

Perhaps of greater concern is the closed kinetic chain situation of the scrum, where the head is constrained from moving and loads are applied at both ends. This can lead to a buckling motion, a process particularly evident in front-row forwards when the scrum collapses and the head strikes the ground. If any single front-row player has comparatively weak cervical extensors, it is reasonable to suggest that this may enhance the risk of scrum collapse. We suggest that specific training may influence this; thus, younger players and perhaps also those returning from cervical injury are potentially at a competitive disadvantage. For the safety of all six front-row players, it is important to recognise, understand and mitigate the biomechanical issues that occur in a closed kinetic chain situation where the forces cannot be vectored away from the spine.

A limitation of this study is the speculative link between cervical strength and scrum collapse and thus injury risk. Although the focus of our investigation was to consider cervical strength parameters, various other factors such as the speed and direction of force application and

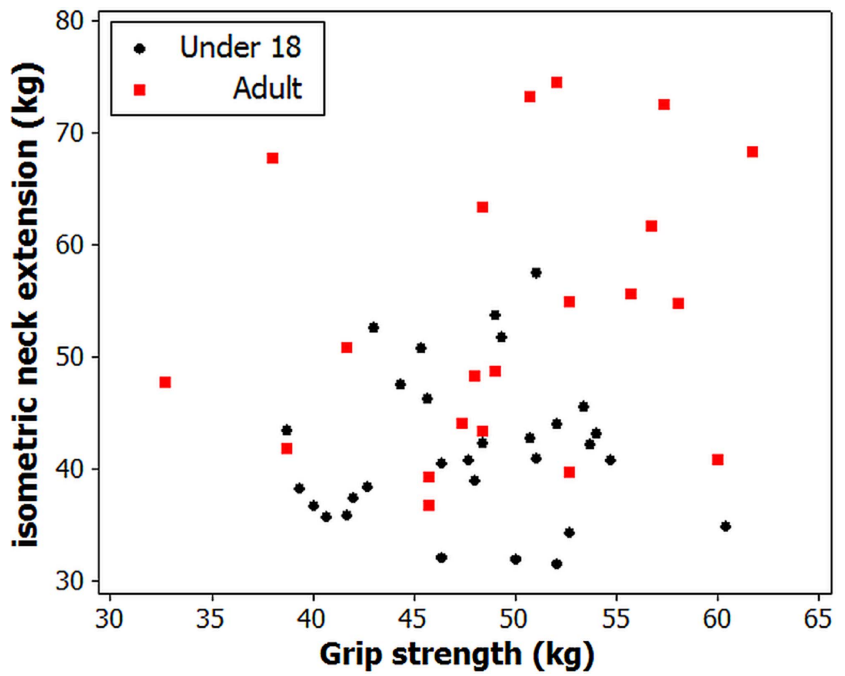

Figure 3 Weak relationship between grip strength and cervical strength. 
Table 3 Multivariate predictive modelling of isometric neck extension $\left(R^{2}=0.31\right)$

\begin{tabular}{lll}
\hline Predictor & Coefficient & $\mathbf{p}$ Value \\
\hline Front-row experience & 0.63 & 0.035 \\
Weight & 0.22 & 0.003 \\
\hline
\end{tabular}

Front-row experience is the primary predictor variable explaining $22 \%$ of the total variation; adding weight as a predictor determines the best-fit model (displayed above). Other variations offer less than $1 \%$ additional enhanced explanatory power with the limitation of comprising more predictor variables and were thus discounted.

orientation of the head/neck complex are also likely to have a bearing on the ability to modulate scrum forces. The neutral anatomic position was chosen for strength and fatigue testing from a safety point of view due to the lack of published data to determine alternative test design. The validity of this test position as the optimal assessment profile for rugby cervical testing is unknown. Future work should focus on the influence of the head position on strength and fatigue values in this context. It must also be recognised that recent changes to the laws of the game surrounding scrum engagement, depowering the contact forces at the onset of the scrum and promoting a sustained pushing contest may influence the playing requirements of the cervical spine of the front rows. It may be that endurance parameters are now more critical than absolute strength characteristics, although further work is required to elaborate on any influence of beneficial physical characteristics as a result of this technical change.

In the elite under-18 group assessed, only 2 of 30 players recorded the mean cervical isometric strength of the adult cohort. Although a few individuals may possess the physical characteristics (and technical skill) to compete with adult players, our results suggest that policy should prevent players under the age of 18 playing in the front row of an adult match, unless specific criteria are met. In contrast to the general schoolboy population, predictive modelling of cervical strength using alternative physical characteristics was poor. As such, specific testing would need to be employed to identify those few individuals able to match their adult counterparts in terms of cervical strength. The concept of a passport to play in the front row is well established in some countries as a means of ensuring that players are appropriately equipped to cope with the rigours of scrummaging. Objective measures of the individuals' cervical strength profile should be an integral part of any selection process for players wishing to play in the front row.

\author{
Author affiliations \\ ${ }^{1}$ Department of Trauma and Orthopaedics, University of Edinburgh, \\ Edinburgh, UK \\ ${ }^{2}$ Gatherer Ltd, Aylesbury, UK \\ ${ }^{3}$ Scottish Rugby Union, Edinburgh, UK \\ ${ }^{4}$ Department of Orthopaedics, Perth Royal Infirmary, Perth, UK
}

Acknowledgements The authors wish to extend thanks to the staff of the Scottish Rugby Union, Professor Jimmy Hutchison and Mr Richard Nutton who facilitated this work, and to all the players who took part in the assessments.
Contributors All authors listed were involved in the study design and data acquisition. DFH performed the analysis and drafted the manuscript. All authors revised and approved the submission.

Funding This research received no specific grant from any funding agency in the public, commercial or not-for-profit sectors.

Competing interests DG has shares in Gatherer Systems who manufactured and supplied the testing equipment used in this study.

Ethics approval Regional ethics committee approval was received for the study through the Fife and Forth Valley REC.

Provenance and peer review Not commissioned; externally peer reviewed.

Data sharing statement No additional data are available.

Open Access This is an Open Access article distributed in accordance with the Creative Commons Attribution Non Commercial (CC BY-NC 3.0) license, which permits others to distribute, remix, adapt, build upon this work noncommercially, and license their derivative works on different terms, provided the original work is properly cited and the use is non-commercial. See: http:// creativecommons.org/licenses/by-nc/3.0/

\section{REFERENCES}

1. Palmer-Green DS, Stokes KA, Fuller CW, et al. Match injuries in English youth academy and schools rugby union: an epidemiological study. Am J Sports Med 2013;41:749-55.

2. Preatoni E, Stokes KA, England ME, et al. The influence of playing level on the biomechanical demands experienced by rugby union forwards during machine scrummaging. Scand J Med Sci Sports 2013;23:178-84.

3. Brooks JHM, Fuller CW, Kemp SPT, et al. Epidemiology of injuries in English Professional rugby union: part 1 match injuries. $\mathrm{Br} J$ Sports Med 2005;39:757-66.

4. Brooks JHM, Fuller CW, Kemp SPT, et al. Epidemiology of injuries in English Professional rugby union: part 2 training injuries. $\mathrm{Br} J$ Sports Med 2005;39:767-75.

5. Mclntosh AS, McCrory P, Finch CF, et al. Head, face and neck injury in youth rugby: incidence and risk factors. $\mathrm{Br} J$ Sports Med 2010;44:188-93.

6. MacLean JG, Hutchison JD. Serious neck injuries in U19 rugby union players: an audit of admissions to spinal injury units in Great Britain and Ireland. Br J Sports Med 2012;46:591-4.

7. Quarrie KL, Cantu RC, Chalmers DJ. Rugby union injuries to the cervical spine and spinal cord. Sports Med 2002; 32:633-53.

8. Brown JC, lambert MI, Verhagen $\mathrm{E}$, et al. The incidence of rugby-related catastrophic injuries (including cardiac events) in South Africa from 2008 to 2011: a cohrot study. BMJ Open 2013;3:e002475.

9. Brooks JHM, Kemp SPT. Injury-prevention priorities according to playing position in professional rugby union players. Br J Sports Med 2011;45:765-75.

10. Gianotti S, Hume PA, Hopkins WG, et al. Interim evaluation of the effect of a new scrum law on neck and back injuries in rugby union. Br J Sports Med 2013;42:427-30.

11. Fuller CW, Brooks JH, Kemp SP. Spinal injuries in professional rugby union: a prospective cohort study. Clin J Sport Med 2007;17:10-16.

12. Roberts SP, Trewartha G, England M, et al. Collapsed scrums and collision tackles: what is the injury risk? Br J Sports Med 2014. Published Online First:10 Feb 2014. doi:10.1136/bjsports-2013092988

13. Scher AT. Rugby injuries to the cervical spine and spinal cord: a 10-year review. Clin Sports Med 1998;17:195-206.

14. Viljoen W, Patricios J. BokSmart-implementing a National Rugby Safety Programme. Br J Sports Med 2012;46:692-3.

15. Nutton RW, Hamilton DF, Hutchison JD, et al. Variation in physical development in schoolboy rugby players: can maturity testing reduce mismatch? BMJ Open 2012;2:e001149.

16. Torg J, Ramsey-Emrhein J. Suggested management guidelines for participation in collision activities with congenital, developmental, or post injury lesions involving the cervical spine. Med Sci Sports Exerc 1997;29:256-72.

17. Hamilton DF, Gatherer D, Jenkins PJ, et al. Age-related differences in the neck strength of adolescent rugby players: a cross-sectional cohort study of Scottish schoolchildren. Bone Jt Res 2012; $1: 152-7$. 
18. Gargés GL, Medina D, Milutinovic L, et al. Normative database of isometric cervical strength in a healthy population. Med Sci Sports Exerc 2002;33:464-70.

19. Jordan A, Mehlsen J, Bülow PM, et al. Maximal isometric strength of the cervical musculature in 100 healthy volunteers. Spine 1999;24:1343-8.

20. Chiu TT, Sing KL. Evaluation of cervical range of motion and isometric neck muscle strength: reliability and validity. Clin Rehabil 2002;16:851-8.
21. Peek K, Gatherer D. The rehabilitation of a professional rugby union player following a C7/T1 posterior microdiscectomy. Phys Ther Sport 2005;6:195-200.

22. Benjamini $Y$, Hochberg $Y$. Controlling the false discovery rate: a practical and powerful approach to multiple testing. $J R$ Stat Soc $B$ 1995;57:289-300.

23. Storey JD. The positive false discovery rate: a Bayesian interpretation and the q-value. Ann Stat 2003;31:2013-35. 